\title{
EPISODES OF ENVIRONMENTAL POISONING WORLDWIDE
}

N J Langford, R E Ferner

Occup Environ Med 2002;59:855-860

The environment is composed of chemical substances, many of which are poisonous if present in large amounts, and some of which are poisonous even in small quantities. Within the industrialised world, specific concentrations of highly dangerous chemicals may be localised to a certain area, vastly increasing the risk to the local environment. Although highly regulated by legislation such as the Control of Major Accident Hazards Regulations 1999 (COMAH), and agencies such as the Health and Safety Executive (HSE) and the Environment Agency (in England and Wales), or the Scottish Environment Protection Agency (SEPA) (in Scotland), industry has been a common source of environmental contamination. Additionally, as we discuss below, manufacturing of chemicals is not the only industrial process that places the environment at risk. Environmental poisoning can also result from the transport, storage, and secondary uses of the primary product.

Small scale releases of toxic chemical substances are common within the industrialised world. ${ }^{1}$ Their impact is usually limited by effective statutory controls and efficient emergency services, but the combination of system failures can lead to disaster. In limiting the impact of such chemical releases, effective communication is required not only between the operator and emergency services but also from the emergency services to the public. Without such communication, panic may ensue, leading to emergency and hospital services being overwhelmed and prevented from effectively pursuing their roles.

The most serious events usually have an immediate impact. Probably the best known example of this was Bhopal, where 2500 people died. However, chemical disasters can also occur where the release of toxins or contamination of products is insidious. This complicates both the detection of the cause of the poisoning and also the management of the environment and those poisoned. At the extreme, a low level continuing release of products can result in the accumulation of a poison both within the environment and within humans, leading to overt symptoms only decades after exposure to the chemical started. Such problems are becoming increasingly common. The time course of the environmental impact is of major importance in determining environmental damage from chemical incidents. We also distinguish between naturally occurring environmental damage by chemicals; damage from human chemical activity; and poisoning through food and drink, which might be susceptible to legislative control and which requires rather different responses. We comment briefly on chemical weapons and warfare.

\section{CHEMICAL INCIDENTS WITH IMMEDIATE IMPACT}

Naturally occurring environmental disasters: volcanic eruptions

These are similar to industrial chemical disasters in many ways. Lake Nyos ${ }^{2}$ is a lake in a volcanic crater in Northwest Cameroon, equatorial Africa. On the night of 21 August 1986, a large gas burst containing up to $10^{9} \mathrm{~m}^{3}$ volcanic gases was released from the lake, and about 1700 people died as a result. The survivors' clinical signs, together with evidence of carbon dioxide in the water, indicates that carbon dioxide from a volcanic source was probably the main lethal gas responsible, and the victims were in effect asphyxiated.

\section{Environmental disasters from human activity} Chemical plant and transport problems

See end of article for authors' affiliations

Correspondence to: Dr R Ferner, West Midlands Centre for Adverse Drug Reaction Reporting, City Hospital, Dudley Road, Birmingham B18 7QH, UK ; r.e.ferner@bham.ac.uk
Ammonia and chlorine

Releases of ammonia and chlorine are common and were in one study more likely to result in evacuations than all other types of releases. ${ }^{3}$ Examples include Lithuania $1989,{ }^{4}$ when an ammonia tank in a fertilizer plant exploded, killing seven people, injuring 57, and leading to the evacuation of 32000 people. However, although fixed facility chemical plants are most likely to be involved in a chemical release $(77 \%)$, there is also significant danger in transporting chemicals $(23 \%)$. For example, when a freight train was derailed in Youngtown, Florida, in 1978, 50 tonnes of chlorine gas escaped, engulfing a local motorway, and killing eight motorists who died from pulmonary toxicity. Overall, 100 people were affected, 23 seriously. 


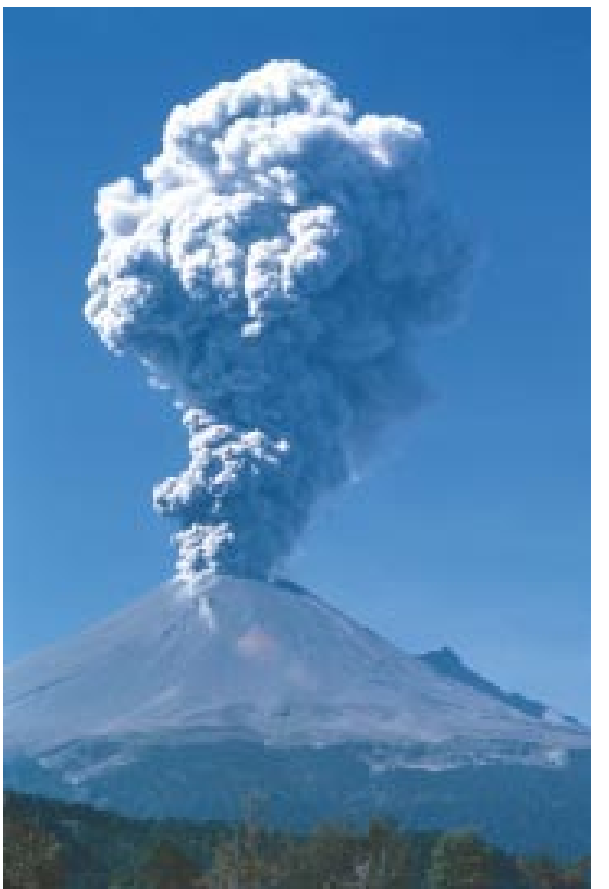

Volcanic eruptions release into the atmosphere large amounts of gases, which can prove lethal to those living nearby. Credit: Wesley Bocxe/SPL.

\section{Bromine}

In November 1984, an accident at a chemical plant in Geneva, Switzerland ${ }^{5}$ released $550 \mathrm{~kg}$ of bromine gas, exposing the public to levels five times the maximal admissible concentration. Ninety one patients attended hospital, though only one was admitted overnight. The most common symptoms were upper respiratory tract irritation, cough, and headache. Telephone calls to the emergency services from members of the public paralysed the city telephone network.

\section{Hydrogen sulfide}

There are many recorded incidents of hydrogen sulfide causing toxicity, both to those occupationally exposed and to the public in general. Examples include Chicago 1978 where sodium sulfide was discharged from a tanker in a tannery tank containing acid. Hydrogen sulfide gas was liberated, leading to seven deaths and multiple injuries. Other examples of the release of hydrogen sulfide gas include an American beachfront construction site, leading to an emergency evacuation, 37 injuries, including long term neurological damage, and one death; problems with sewers in the UK; "cottage" industries in China; and the fishing industry in Japan.

\section{Methyl isocyanate}

Probably the world's worst industrial disaster, involving over 200000 people with approximately 2500 deaths secondary to methyl isocyanate poisoning, occurred when 30-40 tonnes of methyl isocyanate were released from the Union Carbide plant in Bhopal, India ${ }^{6}$ in 1984. The incident resulted from water entering the isocyanate storage tank, causing an exothermic reaction. Owing to a systems failure and poor plant design, normal protective mechanisms failed, allowing release of the gases into the atmosphere, affecting the local population. Local hospitals were overwhelmed with the large number of patients presenting with pulmonary oedema or severe eye irritation. The latter has led to long lasting disability. Problems

\section{Environmental disasters}

- Chemical incidents with immediate impact

- naturally occurring environmental disasters

- environmental disasters from human activity

- food and drink related problems

- war and terrorism

- Chemical incidents causing chronic exposure

- naturally occurring environment disasters

- environmental disasters from human activity

were compounded by confusion over the initial leak and failure to inform the local services. In addition, the toxic properties of isocyanate were not known, leading to confusion over the treatment that patients should receive.

\section{2,3,7,8-tetrachlorodibenzodioxin (TCDD) (dioxin)}

The ICMESA factory at Seveso, Italy manufactured 2,4,5trichlorophenol by an exothermic reaction. On 10 July 1976, the reaction went out of control, leading to a rupture of a plastic disc and the release of $1.3 \mathrm{~kg}$ TCDD. ${ }^{7}$ Although deaths were noted among local birds soon after the event, it took 7-9 days to realise that TCDD was the causative substance. Sixteen days after the initial release local inhabitants were evacuated from the area. Immediate effects were nausea, headache, and eye and skin irritation. Long term effects include a persistent chloroacne. A 10 year follow up study suggested there were no differences in congenital malformation rates between exposed and unexposed populations, though there has been a possible increase in malignancy. Unfortunately, the extent of the disaster will remain unknown owing to the lack of epidemiological evidence, with studies only being started 3-4 years after the event occurred.

\section{Food and drink related problems}

Aluminium sulfide

On 6 July 1988 in Camelford, UK, 20 tonnes of concentrated aluminium sulfate was inadvertently dumped into a water contact tank instead of a storage tank. ${ }^{8}$ This resulted in contamination of the water supply to up to 20000 people. Aluminium concentrations of up to $620 \mathrm{mg} / \mathrm{l}$ were subsequently recorded in the drinking water. In addition, the $\mathrm{pH}$ of the water was reduced, releasing copper, lead, and zinc from plumbing. Although this rendered the water foul tasting people continued to drink the water, and developed nausea, vomiting, diarrhoea, sore eyes, mouth ulcers, and itching skin and rashes. Subsequent toxicological analysis of the water concluded that prolonged toxic effects would not be expected. However, the concerns of the local population were not heeded, with people feeling that important information was denied to them. Chronic sequelae of anxiety and neuropsychiatric disorders have persisted.

\section{Phenol}

Phenol has been associated with various environmental catastrophes, following inadvertent spillages of the compound into various water supplies. Areas concerned have included East Troy, Winsconsin 1974, the River Dee, Wales 1984, and the Nadong River, Korea 1991. Those exposed to increased concentrations of phenol were more likely to suffer from gastrointestinal illnesses, particularly nausea and vomiting, diarrhoea and abdominal pain, though consumption is usually limited owing to the taste of the water.

\section{Toxic oil syndrome}

A previously unknown disease occurred in Spain from 1980 with symptoms consisting of dyspnoea, cough, pruritic rash, 


\begin{tabular}{|c|c|}
\hline Group & Cause \\
\hline I & $\begin{array}{l}\text { Contamination during transport or } \\
\text { storage }\end{array}$ \\
\hline$\|$ & Ingestion of seed dressed for sowing \\
\hline III & Accidental addition of pesticides to fooc \\
\hline IV & Food contaminated by pesticide misuse \\
\hline
\end{tabular}

fever, myalgia, and non-cardiac pulmonary oedema. Over 20000 cases were recorded, with approximately 340 deaths. Initially, the cause was unknown; however, it was eventually linked to cheap rapeseed oil sold by itinerant salesmen. It is hypothesised that the rapeseed had been rendered unfit for human use by the addition of aniline. This was thought to be the causative agent, though doubt remains. Analysis of the contaminated oil was hampered owing to poor specimen collection. A chronic phase of the condition also exists, with muscle wasting, sensorimotor neuropathy, scleroderma and sicca syndrome.

\section{Tri-orthocresyl phosphate}

During Prohibition in the USA between 1930-31, ${ }^{9}$ the alcoholic medicinal product Jamaica Ginger Extract ("Ginger Jake") was widely drunk. Tri-orthocresyl phosphate, an organophosphorous compound, was used in its manufacture. It is thought that 135 gallons of Lyndol (an oily, heat resistant polymer) was used to produce 640000 bottles. Thousands of those who consumed the product developed a flaccid paralysis 10-14 days later. The majority made some recovery, though 50 years later they still had a degree of neurological impairment.

\section{Pesticides}

There are numerous examples of mass pesticide poisoning as a result of contamination of foodstuffs. These have been divided into four distinct groups by Ferrar and Cabral (table 1$).^{10}$

\section{Contamination during transport or storage}

One example with parathion occurred in Jamaica in 1976, when a total of 79 poisonings occurred following the contamination of flour used to make dumplings. The dumplings were found to contain up to $1 \%$ parathion. In total there were 17 deaths. The flour was probably contaminated while being stored next to insecticides in a European warehouse. A similar disaster occurred in Sierra Leone in 1986 involving 49 people of whom 21 died following flour contamination. It appeared that the contamination occurred while the flour was being transported in the back of a truck previously loaded with the pesticide. Flour has also been contaminated with organochlorine pesticides (such as endrin). In Doha, Qatar, and Hofuf, Saudia Arabia in 1967, four outbreaks occurred in two unconnected incidents, in which 874 people were admitted to hospital, and 26 died. In two different ships, flour and endrin had been stored in the same hold. The endrin leaked into the flour, which was later used to make bread. It is estimated that a further 500-750 people were poisoned but symptoms were not severe enough to be admitted.

Ingestion of seed dressed for sowing.

In Turkey, from 1955-61 a major chemical incident involving $10 \%$ hexachlorobenzene occurred, following its use in seed grain as a fungicide. ${ }^{11}$ The grain was not intended for human consumption. A total of 4000 people were affected with porphyria cutanea tarda, a skin disease characterised by bullae on light exposed areas that heal poorly, as well as neurological and orthopaedic problems. The cause of the disease was identified in 1958. However, as the treated seed was unmarked, it continued to be used as a food source until 1961. Once hexachlorobenzene treatment of grain was stopped no new cases were seen.

\section{Accidental addition of pesticides to food}

In Taiwan in 1989, a family party resulted in the poisoning of 13 members of a family, and one death. During the preparation of food for the party, barium carbonate had been used instead of flour. Symptoms consisted of nausea and vomiting, abdominal colic, and diarrhoea.

Food contaminated by pesticide misuse

Aldicarb caused three outbreaks of food poisoning in California, 1985-88, from pesticide residues on watermelons and cucumbers. Symptoms included diarrhoea, vomiting, lacrimation, salivation, miosis, and convulsions.

\section{War and terrorism \\ Chlorine}

On 22 April 1915, 150 tons of chlorine gas was released from German trenches around the village of Ypres in France. A small number of French troops died; however, up to 800 were severely incapacitated. The main symptom was respiratory distress.

\section{Sulfur mustard gas}

This is an alkylating agent, first used in the first world war. Since then it has also been used in other conflicts, most recently in the Iran-Iraq war. The numbers affected are unknown. It damages skin and mucus membranes and damage to the eyes and respiratory tract can be profound and long lasting. However, it has also caused problems apart from military use. Following the second world war, some 100000 tonnes of mustard gas bombs were deposited in the Baltic Sea. Periodically fishermen have suffered from mustard gas poisoning as the bombs have resurfaced in their nets. By 1985, 197 fishermen had been affected, 26 had required hospital admission and two had died.

\section{Phosgene}

This was used as a chemical warfare agent in the first world war. It is more toxic than chlorine, and has poor "warning properties" - sublethal concentrations cause few immediate symptoms and it has little or no odour.

\section{Sarin}

The Germans manufactured the organophosphorus compound sarin as a nerve agent in the second world war. At least two sarin attacks have been reported in Japan in 1994 and 1995. The first affected a residential area in the city of Matsumoto, affecting 600 residents, leading to 58 hospital admissions and seven deaths. ${ }^{12}$ The second, occurring in the Tokyo subway, affected up to 5500 passengers of whom 984 were moderately affected, 17 critically affected, and 12 died. ${ }^{13}$ Symptoms were consistent with organophosphate poisoning, though nicotinic (muscular) responses dominated. Treatment consisted of atropine and pralidoxime.

There are vast stockpiles of chemical agents in various countries around the world. For example, in Russia there are an estimated 40000 tonnes of chemical weapons, enough to 


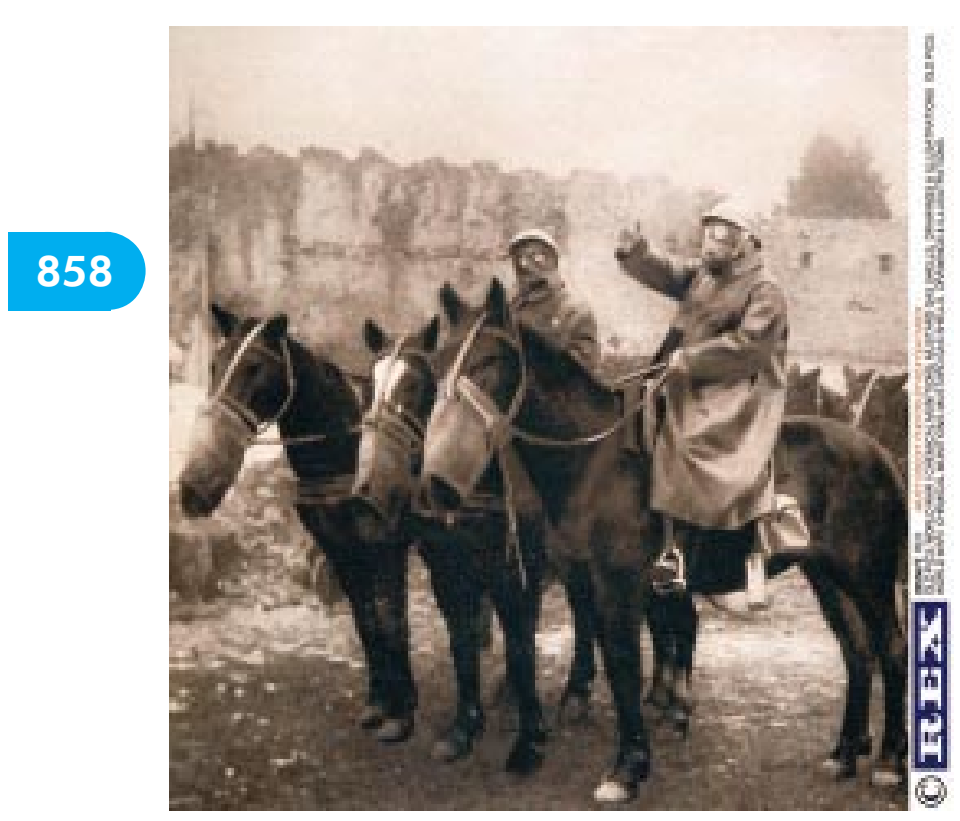

Toxic gases such as chlorine and mustard gas were first used in warfare during the first world war. Credit: Rex Features

kill billions of people. These are waiting to be destroyed. However, it is estimated that it will cost at least US\$6 billion to do so. The stockpiles remain. At least 25 other nations are currently thought have chemical warfare weapons.

\section{CHEMICAL INCIDENTS CAUSING INSIDIOUS EXPOSURE}

\section{Naturally occurring environmental disasters}

Arsenic

Probably the largest environmental disaster to date involved 35-77 million people living in Bangladesh and West Bengal. ${ }^{14}$ In Bangladesh surface water supplies have been contaminated with microorganisms causing significant morbidity and mortality. During the 1970s in an attempt to circumvent this problem, the United Nations Children's Emergency Fund (UNICEF) worked with the Department of Public Health Engineering to insert tube wells to give a safe source of drinking water to the population. In 1983 the first cases of arsenic induced skin lesions were identified. Since then thousands of such cases have been identified in the exposed population. The incidence of internal cancers, particularly those affecting the bladder, genitourinary tract, and lungs, is expected to rise sharply. These tumours have a long latency.

\section{Fluoride poisoning}

Fluoride poisoning occurs within Northern Africa, the Rift Valley system, and in an area extending from Turkey to China. Poisoning usually results from high concentrations of fluoride occurring naturally in the drinking water Concentrations of fluoride greater than $10 \mathrm{mg} / \mathrm{l}$ in drinking water are considered harmful. This has led to skeletal fluorosis and associated skeletal abnormalities. The problem is often compounded by concomitant malnutrition.

\section{Air pollution}

A large amount of air pollution occurs through natural events such as volcanic activity and forest fires. Typical gases emitted include particulate matter as well as sulfur dioxide, methane, carbon monoxide, and nitrogen oxide. These natural events have been associated with an increase in mortality and morbidity as evidenced by the widespread forest fires in Indonesia in 1997. The subsequent smoke cloud affected the neighbouring countries of Malaysia, Singapore, Brunei, Southern Thailand, and parts of the Philippines. Overall there was a significant increase in the number of hospital admissions, particularly for respiratory complaints.

\section{Environmental disasters from human activity \\ Methyl mercury}

The initial cohort was four patients in Minamata Bay, Japan in $1956{ }^{15}$ with an unusual neurological disease, initially thought to be an infectious disorder. Further investigation revealed a link to mercury ingestion. Inorganic mercury was used by a local chemical plant as a catalyst in the production of acetaldehyde (though no responsibility was admitted until 1968). Mercury was discharged in the factory's effluent collecting at the bottom of Minamata bay where it was concentrated and biotransformed to organic mercury by Venus japonica and other local shellfish. By a process of biomagnification, the methylmercury accumulated in increasing amounts in predatory fish, to poison local fisherman whose diet consisted almost entirely of what they had caught in the bay. Symptoms typically consisted of ataxia, constriction of visual fields, and impairment of speech, hearing, and gait. Exposure to the problem was widespread, involving up to 50000 people, with over 2000 of them having certified Minamata disease. In addition there were 28 congenital cases with a syndrome resembling cerebral palsy and an associated IQ below 75, as well as an unknown number of spontaneous abortions.

\section{Cadmium}

Itai-Itai (Ouch-Ouch) disease consists of chronic bone pain (osteomalacia) and renal disease (renal tubules show pronounced atrophy and degeneration) and was first reported in Toyama, Japan in the 1960 s. ${ }^{16}$ In 1968 the Japanese Ministry of Health attributed it to cadmium poisoning, after it was concluded that the Jinzu River was polluted from mines and zinc refineries. The local population used the water to irrigate their rice fields, contaminating the rice with cadmium. Numerous cases of chronic cadmium poisoning have been reported.

\section{Mercury}

Gold mining and refining using elemental mercury is a major industry in the Brazilian Amazon basin. ${ }^{17}$ It is estimated that 100 tons of mercury are released annually. Significant levels of both elemental mercury (from the heating of gold-mercury amalgams) and organic mercury (in river effluents following biotransformation) have been found. This has led to a significant increase in mercury concentrations in both miners and the local fishing population.

\section{Polychlorinated biphenyls}

The Yusho (oil disease) epidemic affected up to 1850 people on the island of Kyusho, Japan in 1968. ${ }^{18}$ Rice oil was contaminated by polychlorinated biphenyls during its manufacture. The syndrome was probably caused by related polychloroquarterphenyls and polychlorodibenzafurans which formed when the oil was fried. The predominant symptoms were chloroacne. Some children born to affected mothers showed evidence of contamination with stained skin and low birth weights; however overall mortality of those exposed over the next 15 years did not increase significantly.

Unprocessed biomass fuels

This is an ongoing problem in India and China. The use of unprocessed fuels for cooking and heating often in poorly 
Lessons learned

- Chemical incidents will continue to happen, placing the general public at risk

- Prior risk assessment will lessen the impact of any chemical incident

- Rapid implementation of major accident plans can reduce morbidity and mortality

- Rescuers need to be aware of exposure risks and problems of secondary contamination

- Good communications are required between rescue organisations and the general public

- Epidemiological follow up of chemical incidents are useful in assessing impact of incident and for future planning

ventilated areas may lead to small areas of high concentrations of particulate matter. Over a period of time, continued exposure to such products can lead to chronic lung problems. Although recently highlighted as a problem in India causing between 400-550 premature deaths a year, the problem has also been shown to exist worldwide. Indeed in China an increase in the incidence of lung cancer has been linked epidemiologically to chronic exposure to cooking on coal stoves.

\section{Processed fossil fuels}

In addition to the burning of unprocessed fuels, within industrialised cities the burning of fossil fuels can cause problems. The most common urban air pollutants include sulfur oxides, nitrogen oxides, carbon monoxide, and ozone. These have all been implicated in exacerbating respiratory conditions.

\section{MEDICAL INVOLVEMENT IN MAJOR DISASTERS}

Following the Seveso disaster, European legislation has been introduced with the intention of preventing major accidents that might result from certain industrial activities, limiting their consequences for man and the environment. ${ }^{19}$ The directive tries to limit the effect of a chemical accident by controlling the placement of chemical sites in urban conurbations and limiting urban development around existing installations. It also stipulates that both the operator and competent authority should have emergency plans drawn up in case of a chemical disaster. Unfortunately, as occurred in Bhopal, chemical factories can be situated in centres of high population, where danger is ever present. In such circumstances a major disaster plan is required by all services that may be involved.

\section{Risk assessment}

The first part of any such assessment is to realise that there is potential risk to the surrounding environment and local population. Risk assessment is the process that evaluates the probability and nature of adverse effects that may occur. It should cover the potential adverse effects the chemical may have. This should include the effects of both acute releases as well as chronic dispersion, and the possibility of bioaccumulation or persistence within the environment. It should also cover the risk of exposure to the individual as well as the overall community. Within the USA the risk of transporting chemicals to the general population is estimated at 1 in 8129000 or 0.12 fatalities per million shipments (compared with the risk of driving at 1 in 6300). However, statistics show that almost $75 \%$ of acute hazardous material events, excluding fuel spills, occur in the fixed locations where the chemicals are used or stored.

\section{In the event of a chemical incident}

To manage a chemical incident effectively, it is necessary to assess the nature and magnitude of the incident, and the initial number of people directly affected, as well as considering who else may be at risk and the resources available. ${ }^{20}$ Initially, emergency personnel need to make a specific identification of the chemical or chemicals involved to ensure not only correct treatment for the patients but also appropriate protection for themselves. The area of contamination and possible contamination has to be marked out, to define those who have probably been exposed and those who may be at future risk, therefore limiting casualties. NIOSH, OSHA, USCG, and EPA recommend dividing the incident area into three zones: the "hot" area encompassing known or suspected contaminated areas, a "warm" zone acting as a decontamination corridor, and a "cold" zone free of contamination. The warm zone is also important in helping to limit spread of the agent, with no one passing from the contaminated zone to the clean zone without being decontaminated. Monitoring of the zones is important to ensure they have been appropriately set up and are wide enough to protect the public.

Following a chemical disaster, the victims will usually present to the emergency department. The number of victims seeking treatment may initially overwhelm those hospitals nearest the accident. Within the UK most hospitals who receive acute admissions have a major accident plan they are able to implement, in conjunction with the other aid services.

Those treating the victims of an incident, especially if they are within the contamination zone, are required to take measures to protect themselves. In certain incidents they may need protective equipment to protect airways, skin, and eyes. However, full personal protective equipment can make it difficult to perform first aid, and the wearer can develop dehydration, heat related illness, and adverse physiological effects. All affected victims have to be decontaminated before effective treatment so as to reduce potential absorption of toxins through the skin and to rescuers. The problem of secondary contamination is real-for example, in the Tokyo subway attack, 8 out of 53 rescuers and at least one physician in a local hospital were affected by secondary contamination. A triaging system will also be required at the scene of an incident to allow resources to be directed appropriately.

As was the case with the Tokyo subway attack, a large number of those presenting to the hospital may not have been physically affected by the incident. It is important that the hospital sets up a system of triage to enable resources to be targeted to those at greatest need.

Once within the hospital it is important to establish the nature of the chemical, so exact treatment and antidotes can be administered. A network of regional poison centres exists within the UK and is able to give advice about treatment and antidotes available. In addition the International Programme on Chemical Safety in conjunction with the World Health Organization and other organisations via the Intox programme has been established to assist poison centres and related institutions in the prevention of poisoning, saving of lives, and minimising the adverse health effects resulting from toxic exposures. These organisations are able to advise not only on treatment to be given, but also on the availability and supplies of specific antidotes and other drugs.

\section{Post-incident}

After the event has occurred, ongoing monitoring of the situation is required to be able to catalogue the extent of the disaster as well as assessing the long term implications and complications that may occur. An epidemiological review of the 


\section{Medical management of a chemical incident}

- Before an incident:

- contribute to risk management assessment

- anticipate potential hazards

- ensure antidotes to chemicals used locally are available

In the event of a chemical incident:

- evaluate the health risk

- triage at incident and on arrival to hospital

- manage those exposed

- treat casualties

- prevent secondary spread

- reassure exposed and general public

- collaborate with national and international agencies

- Post exposure:

- set up clinical and epidemiological follow up as necessary

situation is useful to ensure lessons can be learned and those exposed can be followed up appropriately.

More detailed information on management of incidents involving specific chemicals can be found elsewhere. ${ }^{21-23}$

\section{CONCLUSION}

Chemical spills are common. If managed appropriately, however, the impact on the environment and human life may be minimised.

\section{Authors' affiliations}

*N J Langford, Clinical Pharmacology Section, Department of Medicine, University of Birmingham, Queen Elizabeth Hospital, Birmingham, UK tR E Ferner, West Midlands Centre for Adverse Drug Reaction Reporting, City Hospital, Birmingham, UK

*Also West Midlands Centre for Adverse Drug Reaction Reporting, Birmingham

†Also Clinical Pharmacology Section, Department of Medicine, University of Birmingham

\section{REFERENCES}

1 International Programme on Chemical Safety. Hazardous chemicals in human and environmental health: a resource book for school, college and university students. Geneva: World Health Organization, 2000.

2 Wagner GN, Clark MA, Koenigsberg EJ, et al. Medical evaluation of the victims of the 1986 Lake Nyos disaster. J Forensic Sci 1988;33:899-909.

3 Hall I, Haugh G, Price-Green P, et al. Risk factors for hazardous substance release that result in injuries and evacuations: data from 9 states. Am J Public Health 1996;86:855-7.

4 Andersson B. Lithuanian ammonia incident. ICHEME Symposium Series No. 1241990.

5 Morabia A, Selleger C, Landry JC, et al. Accidental bromine exposure in an urban population: an acute epidemiological assessment. Int J Epidemiol 1988; 17:148-52.

6 Anon. Calamity at Bhopal. Lancet 1984;ii:1378-9.

7 Bertazzi PA, Zocchetti C, Pesatori AC, et al. Ten-year mortality study of the population involved in the Seveso incident in 1976. Am J Epidemiol 1989;129:1187-200.

8 Anon. After Camelford. Lancet 1989;ii:288

9 Morgan JP. The Jamaica ginger paralysis. JAMA 1982;248:1864-7.

10 Ferrer A, Cabral R. Recent epidemics of poisoning by pesticides. Toxicology Letters 1995;82-83:55-63.

11 Cam C, Nigogosyan G. Acquired toxic porphyria cutaena tarda due to hexachlorobenzene. Report of 348 cases caused by this fungicide. JAMA 1963;183:88-91.

12 Morita H, Yanagisawa N, Nakajima T, et al. Sarin poisoning in Matsumoto, Japan. Lancet 1995;346:290-3.
13 Woodall, J. Tokyo subway gas attack. Lancet 1997:350:296.

14 Smith AH, Lingas EO, Rahman M. Contamination of drinking-water by arsenic in Bangladesh: a public health emergency. Bull WHO 2000;78:1093-1103.

15 Tsubaki T, Irukayama K. Minamata disease. Amsterdam: Elsevier Scientific, 1977.

16 Tsuchiya K. Epidemiological studies on cadmium in the environment in Japan: etiology of itat-itai disease. Fed Proc 1976;35:2412-18.

17 Epstein PR. Mercury poisoning. Lancet 1991;337:1344.

18 Kuratsune $M$, Yoshimura T, Matsuzaka J, et al. Yusho, a poisoning caused by rice oil contaminated with polychlorinated biphenyls. HSMHA Health Reports 1971;86:1083-91.

19 The Council of the European Union. Council Directive 96/82/EEC (Seveso II Directive), 1996.

20 Brennan RJ, Waeckerle JF, Sharp TW, et al. Chemical warfare agents: emergency medical and emergency public health issues. Ann Emerg Med 1999;34:191-204.

21 Toxnet. National Library of Medicine. http://toxnet.nlm.nih.gov/

22 Canada's National Centre for Occupational Health and Safety

Information. http://www.ccohs.ca/

23 ATSDR. Managing hazardous materials incidents. http:// www.atsdr.cdc.gov/mhmi.html.

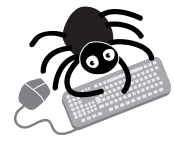

Additional references appear on the Occupational and Environmental Medicine website-www.occenvmed.com

\section{QUESTIONS (SEE ANSWERS ON P 793)}

For each question please indicate which answers are true or false

(1) Which of the following can cause neurological damage after chronic ingestion?
(a) tetraethyl lead
(b) tri-ortho cresyl phosphate
(c) methyl mercury
(d) sodium arsenate
(e) potassium chloride

(2) Following a chemical incident what immediate actions should be taken?

(a) set up appropriate triage areas

(b) evaluate the health risk

(c) notify the general public of the incident

(d) start an epidemiological survey

(e) treat casualties

(3) Which of the following chemicals are frequently involved in acute chemical poisonings?
(a) ammonia
(b) mercury
(c) chlorine
(d) polychlorinated biphenyls
(e) bromine

(4) Which of the following are true?

(a) biotransformation of mercury by shellfish can potentiate its human toxicity

(b) porphyria cutanea tarda can be caused by tri-ortho cresyl phosphate poisoning

(c) sulfur dioxide, carbon dioxide, and selenium dioxide are important pollutants generated by burning fossil fuels

(d) fluorosis mainly affects the kidneys

(e) phosgene has poor warning properties 